\title{
Glutathione-capped Syzygium cumini carbon dot-amalgamated agarose hydrogel film for naked-eye detection of heavy metal ions
}

\author{
Jigna R. Bhamore', Tae Jung Park² and Suresh Kumar Kailasa ${ }^{1 *}$ (D)
}

\begin{abstract}
Development of a facile and sensitive analytical tool for the detection of heavy metal ions is still a challenging task because of interference from other chemical species. In this work, glutathione (GSH)-capped Syzygium cumini carbon dots (CDs) have been integrated with agarose hydrogel film and used as an amalgamated solid probe for sensing of different metal ions $\left(\mathrm{Pb}^{2+}, \mathrm{Fe}^{3+}\right.$, and $\left.\mathrm{Mn}^{2+}\right)$. The synthesis of a solid sensing platform is based on the electrostatic interactions between GSH-capped Syzygium cumini CDs and agarose hydrogel. The developed hydrogel-based solid probe exhibited good linearities with the concentration ranges of metal ions from 0.005 to $0.075,0.0075$ to 0.1 , and 0.0075 to $0.1 \mathrm{mM}$ with detection limits of $1.3,2.5$, and $2.1 \mu \mathrm{M}$ for $\mathrm{Pb}^{2+}, \mathrm{Fe}^{3+}$, and $\mathrm{Mn}^{2+}$ ions, respectively.
\end{abstract}

Keywords: GSH-capped CDs-hydrogel, Metal ions, UV-visible and fluorescence spectrometry

\section{Introduction}

Heavy metal ions have been considered as potential agents to contaminate various environments including water, soil, and air (Gong et al. 2016). Even at low concentrations, they exhibited a highly toxic nature and caused serious health problems in various living systems (Gong et al. 2016; Callender 2003; Roy 2010). Heavy metal ions are effectively accumulated in various living organisms and seriously damaged various organs/systems including the nervous, immune, reproductive, and gastrointestinal systems (Afkhami et al. 2013; Gumpu et al. 2015). Among the metals ions, cadmium, lead, chromium, mercury, and arsenic have been recognized as potential toxic agents to ecology (Pujol et al. 2014; Prabhakar et al. 2012; Kim et al. 2012; Bernalte et al. 2011). Therefore, it is highly desirable to develop a simple analytical strategy for the detection of the above metal ions in environmental water samples. Furthermore, various

\footnotetext{
*Correspondence: sureshkumarchem@gmail.com; skk@chem.svnit.ac.in 'Department of Applied Chemistry, S. V. National Institute of Technology, Surat 395007, India

Full list of author information is available at the end of the article
}

international organizations such as the World Joint Food and Agricultural Organization, the Health Organization, the Centre for Disease Control, the US Environmental Protection Agency, and the European Union have set the maximum permissible limit of their concentration in water by following the environment quality standards (Gumpu et al. 2015; WHO, Guidelines for Drinking-water Quality, 4th edition 2011; Directive, 2013/35/EU of the European Parliament and of the Council 2013; Standard methods for the examination of water and wastewater 2012). In view of this, the identification of trace-level metal ions plays a key role in the monitoring of toxic metal ions in various environmental and food samples.

To identify the above metal ions, various spectroscopic techniques including inductively coupled plasma mass spectroscopy (Wang et al. 2015), atomic absorption spectroscopy (Pohl 2009; Trindade et al. 2015; Kenawy et al. 2000), X-ray fluorescence spectrometry (Sitko et al. 2015), and neutron activation analysis and inductively coupled plasma optical emission spectrometric (Losev et al. 2015) have been used for the quantification of metal ions in 
multifaceted matrices at nanomolar concentrations. However, these techniques are very costly and involved tedious sample preparations with skilled persons. Further, some of the techniques are needed to be coupled with chromatographic techniques for the separation and identification of metal ions from various environments (Array and Merkoci 2012). Therefore, it is essential to establish a simple visual analytical tool for the selective detection of the above metal ions in various environments (Cui et al. 2015).

Hydrogels are crosslinked 3D network structures that belong to soft materials. Recently, hydrogels have been integrated with various analytical applications including drug delivery and sensing of various chemical species (Ullah et al. 2015). To support this, hydrogel-based refractive index, resonance frequency, and optical transmission tools have been developed for sensing various molecules (Lin et al. 2011). Moreover, $\mathrm{Cu}^{2+}, \mathrm{Pb}^{2+}$, and $\mathrm{Ag}^{+}$ions were visually detected by fabricating hydrogels, and the method was able to detect metal ions even at a nanomolar concentration (Hong et al. 2011). To enhance the sensing ability of hydrogels, recently, various nanostructured materials and biomolecules have been incorporated into hydrogels and used as a probe for sensing of various chemicals species (Gogoi et al. 2015; Ye et al. 2012; Nam et al. 2018; Yan et al. 2017; Zhu et al. 2010). Apart from these reports, upconversion nanoparticles have also been used as probes for the detection of various metal ion (Gu and Zhang 2018; Gu et al. 2018; Gu et al. 2016a; Gu et al. 2016b).

Herein, hydrogel-based visual strips have been fabricated for the detection of metal ions $\left(\mathrm{Pb}^{2+}, \mathrm{Fe}^{3+}\right.$, and $\left.\mathrm{Mn}^{2+}\right)$ by incorporating glutathione (GSH)-capped fluorescent $\mathrm{CDs}$ into hydrogels. In this work, fluorescent CDs were fabricated from Syzygium cumini fruits and then functionalized with GSH. The agarose hydrogel-based visual strip was prepared by incorporating GSH CDs into a hydrogel and then used as a solid probe for the detection of three metal ions, i.e., $\mathrm{Pb}^{2+}, \mathrm{Fe}^{3+}$, and $\mathrm{Mn}^{2+}$ ions. The developed hydrogelbased solid strip offers a simple analytical platform for onsite visual detection of the three metal ions. The color intensity was progressively increasing with increasing concentration of metal ions. The developed GSH CD-agarose hydrogel can be used as a promising solid strip for on-thespot visual detection of the three metal ions without the aid of a sophisticated instrument.

\section{Experimental section Materials}

Agarose low gelling was purchased from Sisco Research Laboratories Pvt. Ltd., India. The Syzygium cumini fruits were purchased from the local market, Surat, India. The metal precursors such as $\mathrm{Mn}\left(\mathrm{NO}_{3}\right)_{2} \cdot 6 \mathrm{H}_{2} \mathrm{O}, \mathrm{Pb}\left(\mathrm{NO}_{3}\right)_{2}, \mathrm{Cu}\left(\mathrm{NO}_{3}\right.$ )$_{2} \cdot 3 \mathrm{H}_{2} \mathrm{O}, \mathrm{Cd}\left(\mathrm{NO}_{3}\right)_{2} \cdot 4 \mathrm{H}_{2} \mathrm{O}, \mathrm{Hg}\left(\mathrm{NO}_{3}\right)_{2} \cdot \mathrm{H}_{2} \mathrm{O}, \mathrm{FeCl}_{3} \cdot 6 \mathrm{H}_{2} \mathrm{O}, \mathrm{Co}$ $\left(\mathrm{NO}_{3}\right)_{2} \cdot 6 \mathrm{H}_{2} \mathrm{O}, \mathrm{Cr}\left(\mathrm{NO}_{3}\right)_{2} \cdot 6 \mathrm{H}_{2} \mathrm{O}$, and $\mathrm{GSH}$ were purchased from Sigma-Aldrich, USA. Dialysis membrane-70 was purchased from Hi-Media Laboratories Pvt. Ltd., India. All experiments were performed by using MilliQ-purified water.

\section{Instrumentation}

UV-visible absorption and fluorescence spectra of CDs were measured by using Maya Pro 2000 spectrophotometer (Ocean Optics, USA) and Cary Eclipse Fluorescence Spectrophotometer (Agilent Technologies, USA) equipped with the Xenon flash lamp. Fourier transform infrared (FT-IR) spectra were recorded on a Shimadzu (FT-IR, Bruker, USA). The size and morphology of CDs were examined by HR-TEM on a JEOL 3010 with an accelerating voltage of $200 \mathrm{kV}$. dynamic light scattering (DLS) measurements were performed by using Zetasizer Nano ZS90 (Malvern, UK).

\section{Synthesis of CDs from Syzygium cumini and then functionalizations with GSH}

Water-dispersible fluorescent CDs were derived from Syzygium cumini fruits by one-step hydrothermal treatment (Bhamore et al. 2016). Briefly, $15 \mathrm{~mL}$ of Syzygium cumini fruit juice was taken into a reaction flask that contains $85 \mathrm{~mL}$ of water. The reaction flask was inserted in autoclave reaction, and then carbonization was carried out at $180{ }^{\circ} \mathrm{C}$ for $6 \mathrm{~h}$. The obtained black residue was dialyzed against Milli-Q-purified water for $6 \mathrm{~h}$ using a dialysis membrane (molecular weight cut off $=70 \mathrm{kDa}$ ). The isolated $\mathrm{CDs}$ were stored at $4{ }^{\circ} \mathrm{C}$ for further use. Further, the GSH was used as a capping agent for functionalizations of CDs. In this, $5 \mathrm{mM}$ of $2.5 \mathrm{~mL}$ GSH was added to $20 \mathrm{~mL}$ of as-prepared CDs, and then the solution was stirred for $3 \mathrm{~h}$.

\section{Preparation of agarose hydrogel film}

Agarose hydrogel was prepared by modifying the procedure described by Gogoi et al. Simply, 2.5\% (w/v) of agarose solution was prepared by dissolving $0.25 \mathrm{~g}$ of agarose in $10 \mathrm{~mL}$ of $0.1 \mathrm{M} \mathrm{NaOH}$ solution. Then, the above solution was microwave heated at $180{ }^{\circ} \mathrm{C}$ for $30 \mathrm{~s}$ to dissolve the agarose. To form the film, the obtained solution was poured onto a petri dish and kept it for $12 \mathrm{~h}$ at room temperature.

\section{Preparation of GSH-capped CD agarose hydrogel film}

The GSH-capped CD-amalgamated agarose hydrogel was prepared by the following procedure. To this, $2.5 \%$ $(\mathrm{w} / \mathrm{v})$ of agarose was taken into a reaction beaker that contained $10 \mathrm{~mL}$ of GSH CDs and $1.0 \mathrm{M}$ of $\mathrm{NaOH}$ solution $(1: 1 \mathrm{v} / \mathrm{v})$. The solution was microwave heated for $30 \mathrm{~s}$ at $180 \mathrm{~W}$. The hydrogel film was prepared by pouring the above solution into the petri dish and followed by drying at room temperature for $12.0 \mathrm{~h}$. 


\section{Visual detection of metal ions}

In order to examine the visual detection ability of prepared hydrogel towards metal ions, the GSH CD-agarose hydrogel film was cut into $2.0 \times 2.0 \mathrm{~cm}$ and then the films were dipped separately into various metal ion solutions $\left(\mathrm{Pb}^{2+}\right.$, $\mathrm{Fe}^{3+}, \mathrm{Mn}^{2+}, \mathrm{Cr}^{3+}, \mathrm{Hg}^{2+}, \mathrm{Cu}^{2+}, \mathrm{Cd}^{2+}$, and $\mathrm{Co}^{2+}$ ions, 1.0 $\mathrm{mM}$ ) and kept them stand for $12 \mathrm{~h}$ at room temperature. The dipped hydrogel films were dried, and their photographic images were measured by a digital camera. It was noticed that only $\mathrm{Pb}^{2+}, \mathrm{Fe}^{3+}$, and $\mathrm{Mn}^{2+}$ ions were significantly induced color changes of GSH CD-hydrogel film.

To establish a hydrogel film-based analytical strategy, various concentrations of $\mathrm{Pb}^{2+}, \mathrm{Fe}^{3+}$, and $\mathrm{Mn}^{2+}$ ions (0.005-1.0, 0.0075-1.0, and 0.0075-1.0 mM) were prepared and then the GSH CD-hydrogel films were treated with the above metal ion concentrations for $12.0 \mathrm{~h}$ at room temperature. The color changes of GSH CD-hydrogel films were measured by a digital camera and were measured by the ImageJ program by quantifying relative to the background of hydrogel film without the three metal ions.

\section{Results and discussion}

A green and one-step synthetic method was developed for the fabrication of GSH-capped CD agarose hydrogel film. The fabricated hydrogel film was used as a solid probe for visual detection of the three metal ions $\left(\mathrm{Pb}^{2+}, \mathrm{Fe}^{3+}\right.$, and $\mathrm{Mn}^{2+}$ ) (Scheme 1). Initially, fluorescent CDs were fabricated from Syzygium cumini fruits and then capped with GSH. To confirm the formation of CDs and GSH-capped $\mathrm{CDs}$, the spectroscopic techniques (UV-visible, fluorescence, and FT-IR) were studied for the characterization of CDs and GSH CDs. Figure 1 shows the absorption spectra of CDs derived from Syzygium cumini fruits, GSH, and GSH-capped CDs. The UV-visible absorption spectra of the above compounds show maximum absorbance at 312 , 299, and $316 \mathrm{~nm}$ for CDs, GSH, and GSH-capped CDs, respectively. The as-synthesized CDs exhibited absorption spectrum at $312 \mathrm{~nm}$ which is due to $\pi-\pi^{\prime \prime}$ and $n-\pi^{*}$ transitions in CDs. The GSH-capped CDs showed tremendous excitation-dependent emission spectra by exciting at various excitation wavelengths. The distinctive red shift was observed in the emission wavelength upon the excitation at different wavelengths from 340 to $440 \mathrm{~nm}$ (Supporting Information of Figure S1). As shown in Supporting Information of Figure S2, the GSH-capped CDs exhibited fluorescence emission spectrum at $453 \mathrm{~nm}$ when excited at $370 \mathrm{~nm}$ with a quantum yield of $6.1 \%$.

The morphology and size of CDs derived from Syzygium cumini fruits were investigated by using HR-TEM and DLS. As shown in Fig. 2a, b, the size of the as-synthesized CDs was $2.1 \pm 0.7 \mathrm{~nm}$, which was calculated from the histogram graph of HR-TEM. The DLS data also confirm that the mean size of CDs was $3.1 \pm 0.5 \mathrm{~nm}$ and GSHcapped CDs was $4.2 \pm 0.3 \mathrm{~nm}$ (Supporting Information of

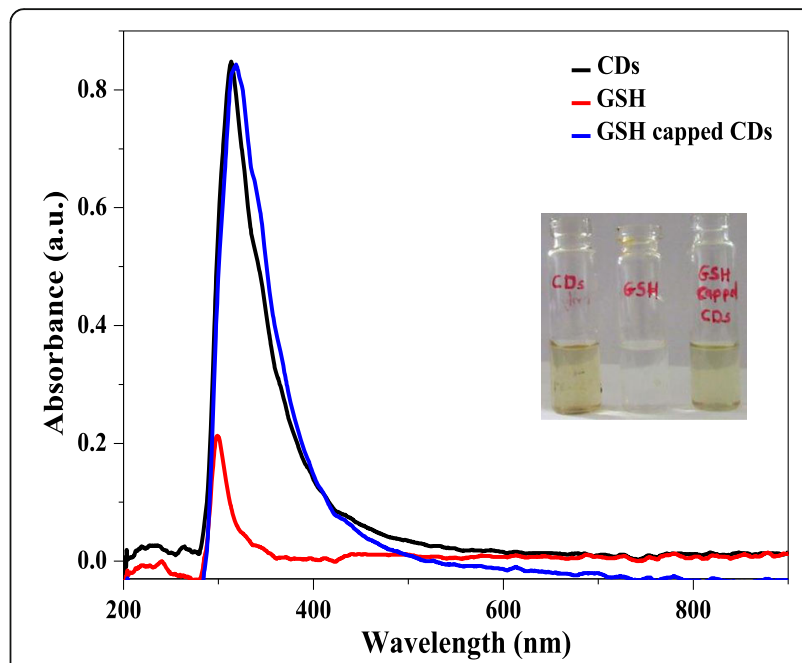

Fig. 1 UV-visible absorption spectra of CDs, GSH, and GSH-capped CDs

Figure S3), which is well-matched with HR-TEM data. As displayed in Supporting Information of Figure S4, the zeta potential of GSH-capped CDs was observed at $47.1 \mathrm{mV}$. Importantly, it can be noticed that there are slight changes in the UV-visible absorption and fluorescence spectra of CDs and GSH CDs, suggesting the functionalizations of CDs with GSH molecules.

Further, the FT-IR spectra of CDs, GSH, and GSHcapped CDs are shown in Fig. 3. The peak at $3418 \mathrm{~cm}^{-1}$ represents the $\mathrm{O}-\mathrm{H}$ stretching of $\mathrm{CDs}$. The characteristic peaks at 2925 and $1400 \mathrm{~cm}^{-1}$ correspond to the $-\mathrm{C}-\mathrm{H}$ stretching and bending of CDs. Similarly, the $-\mathrm{C}=\mathrm{O}$ stretching of CDs was observed at $1625 \mathrm{~cm}^{-1}$. As shown in the GSH FT-IR spectrum in Fig. 3 (b), stretching of the N$\mathrm{H}, \mathrm{S}-\mathrm{H}$, and $-\mathrm{C}=\mathrm{O}$ groups was observed at 3346, 2521, and $1715 \mathrm{~cm}^{-1}$, respectively. The $\mathrm{C}-\mathrm{H}$ and $\mathrm{O}-\mathrm{H}$ group bending was observed at 1398 and $923 \mathrm{~cm}^{-1}$, respectively. After capping with $\mathrm{GSH}$, the $-\mathrm{O}-\mathrm{H} /-\mathrm{N}-\mathrm{H}$ stretching was observed at $3423 \mathrm{~cm}^{-1}$ and the stretching of $-\mathrm{C}=\mathrm{O}$ peak was slightly shifted to $1633 \mathrm{~cm}^{-1}$ (Fig. 3 (c)), confirming the formation of GSH CD-hydrogel. These structural features play a significant role to incorporate GSH CD nanostructures into agarose hydrogels, which can be fabricated as a solid probe for visual detection of metal ions.

\section{GSH-capped CD-agarose hydrogel as a visual sensor}

In order to examine the distinctive analytical application of prepared hydrogel film, first, the visual detection ability of bare agarose hydrogel film and GSH-capped CDagarose hydrogel film were studied by keeping $2.0 \times 2.0$ $\mathrm{cm}$ films (thickness $\sim 0.3 \mathrm{~mm}$ ) separately into various metal ion $\mathrm{Pb}^{2+}, \mathrm{Fe}^{3+}, \mathrm{Mn}^{2+}, \mathrm{Cr}^{3+}, \mathrm{Hg}^{2+}, \mathrm{Cu}^{2+}, \mathrm{Cd}^{2+}$, and $\mathrm{Co}^{2+}$ ions, $1.0 \mathrm{mM}$ ) solutions. The color changes were monitored by taking photographic images by a digital camera (Fig. 4). It can be noticed that the bare agarose 


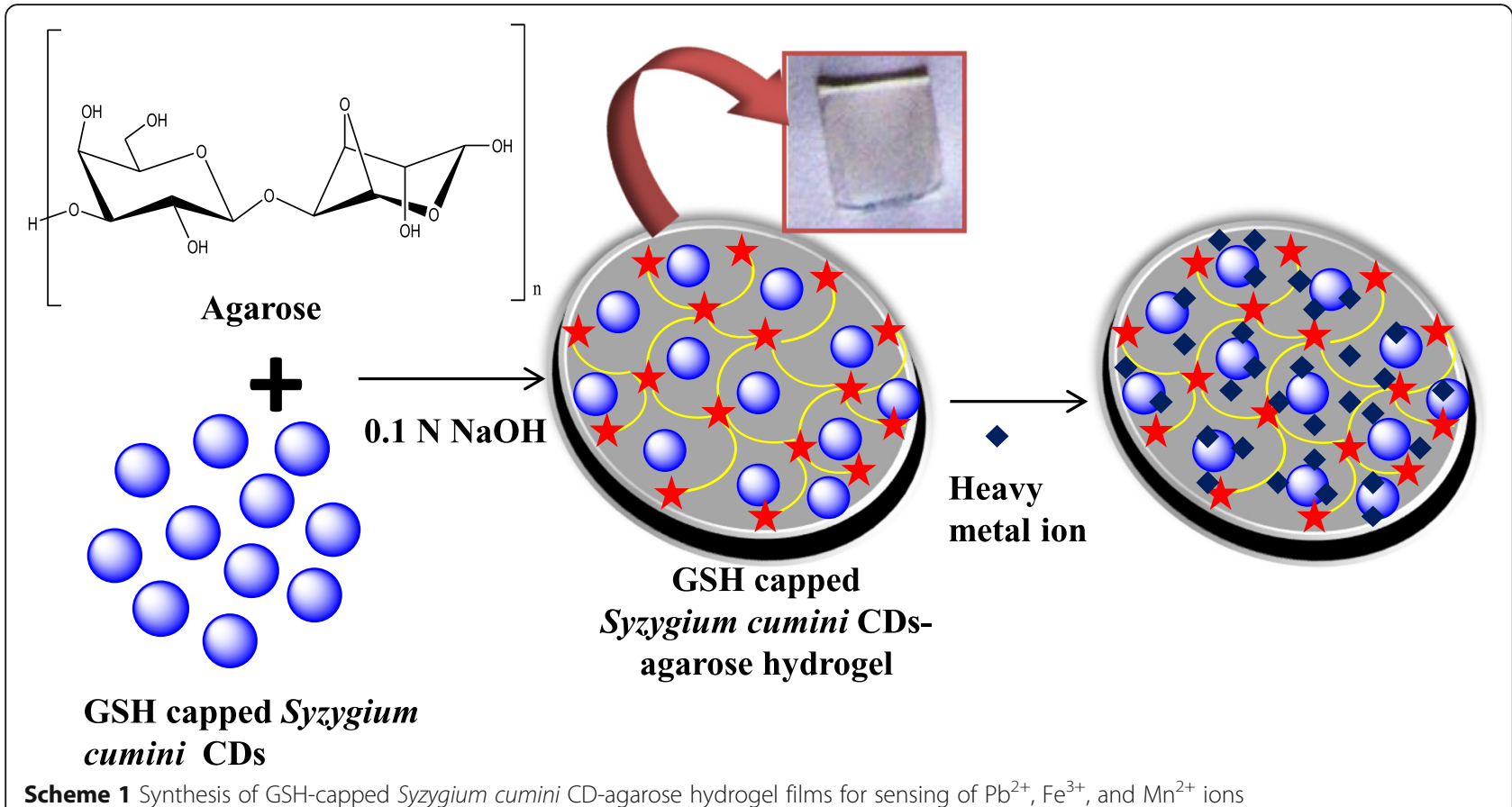

hydrogel film did not show any visual changes when treated with metal ions. However, the GSH-capped CDagarose hydrogel film showed distinct color changes only with three metal ions $\left(\mathrm{Pb}^{2+}, \mathrm{Fe}^{3+}\right.$, and $\left.\mathrm{Mn}^{2+}\right)$. The color of GSH CD-hydrogel film was changed to white, brown, and dark brown colors for $\mathrm{Pb}^{2+}, \mathrm{Fe}^{3+}$, and $\mathrm{Mn}^{2+}$ ions, respectively. These color changes are due to the formation of metal GSH CD-hydrogel complexes, which can be visualized with the naked eye. The other metal ions $\left(\mathrm{Cr}^{3+}\right.$, $\mathrm{Hg}^{2+}, \mathrm{Cu}^{2+}, \mathrm{Cd}^{2+}$, and $\mathrm{Co}^{2+}$ ions) showed negligible color changes, indicating that GSH CD-modified hydrogel acts as a solid probe for visual detection of $\mathrm{Pb}^{2+}$, $\mathrm{Fe}^{3+}$, and $\mathrm{Mn}^{2+}$ ions.
Sensitivity study for the visual detection of three metal ions with GSH-capped CD-agarose hydrogel film as a solid probe

In order to establish the analytical platform for the three metal ions individually, different concentrations of the three metal ions $\left(\mathrm{Pb}^{2+}, 0.005-1.0 \mathrm{mM} ; \mathrm{Fe}^{3+}, 0.0075-1.0\right.$ $\left.\mathrm{mM} ; \mathrm{Mn}^{2+}, 0.0075-1.0 \mathrm{mM}\right)$ were taken separately into sample vials and then treated with GSH-capped CDagarose hydrogel $(2.0 \times 2.0 \mathrm{~cm}$, thickness $\sim 0.3 \mathrm{~mm})$ for $12 \mathrm{~h}$. The metal ion-treated hydrogel film strips were taken out, and then their color changes and color intensities were measured for the quantification of the three metal ions (Fig. 5). The color changes $\left(\mathrm{Pb}^{2+}\right.$ ion $\rightarrow$ white,
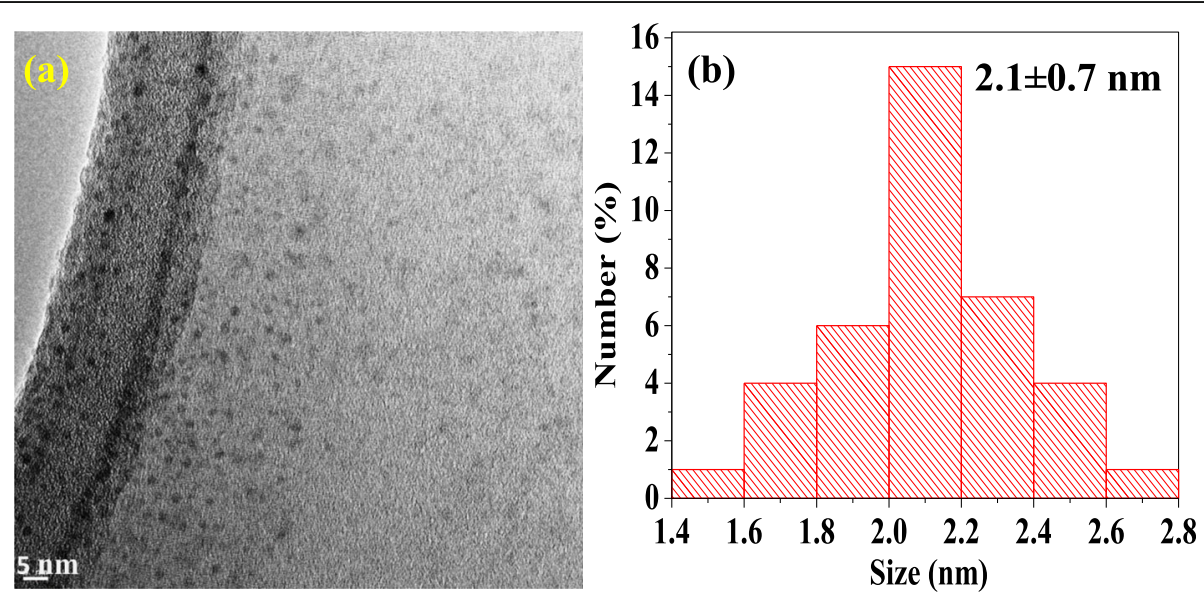

Fig. 2 a HR-TEM image of CDs derived from Syzygium cumini fruits. b Histogram graph plotted from the HR-TEM image at $5 \mathrm{~nm}$ scale bar 


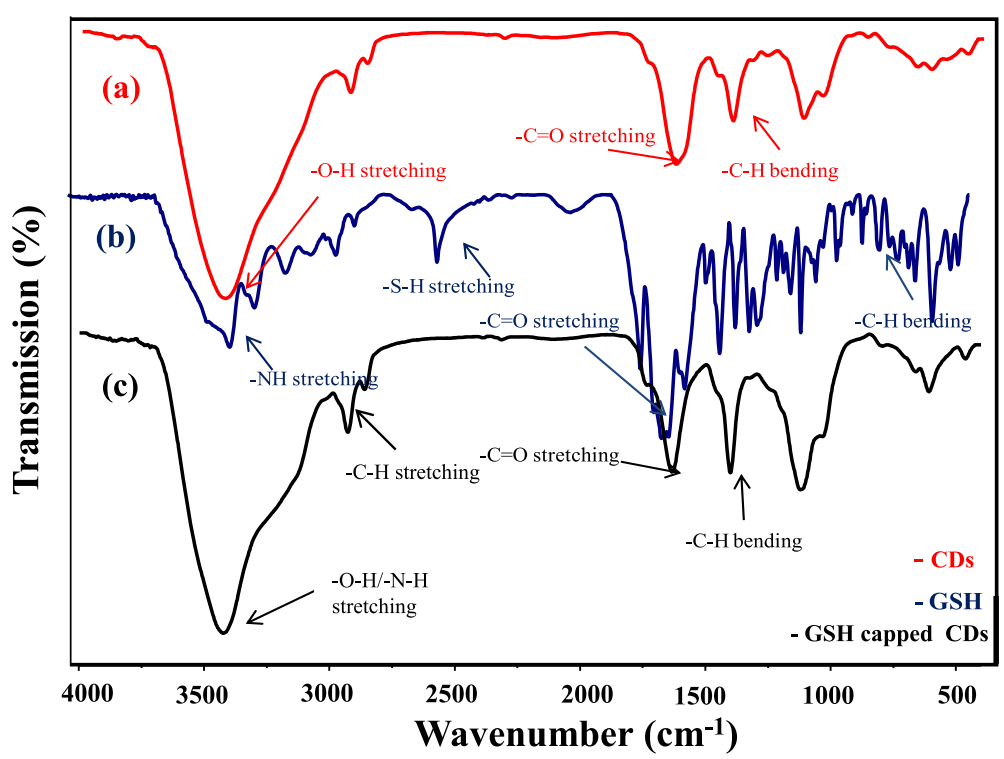

Fig. 3 FT-IR spectra of (a) CDs, (b) GSH, and (c) GSH-capped CDs

$\mathrm{Fe}^{3+}$ ion $\rightarrow$ brown, and $\mathrm{Mn}^{2+}$ ion $\rightarrow$ dark brown) were progressively increased with increasing concentration of metal ions, which can be noticed with the naked eye. The color intensities of metal ion-treated hydrogel films were measured (before and after immobilization to GSH CD-hydrogel film) by analyzing them with the ImageJ software, and then calibration graphs were constructed between color intensities and the concentrations of the three metal ions. As a result, good linearities were observed between the color intensities and the concentration ranges of $0.005-0.075 \mathrm{mM}$ for $\mathrm{Pb}^{2+}$ ion and
0.0075-0.1 $\mathrm{mM}$ for $\mathrm{Fe}^{3+}$ and $\mathrm{Mn}^{2+}$ ions with a correlation coefficient of $0.9891,0.9915$, and 0.9873 for $\mathrm{Pb}^{2+}$, $\mathrm{Fe}^{3+}$, and $\mathrm{Mn}^{2+}$ ions, respectively (Fig. 6). The detection limits were $1.3,2.5$, and $2.1 \mu \mathrm{M}$ for $\mathrm{Pb}^{2+}, \mathrm{Fe}^{3+}$, and $\mathrm{Mn}^{2+}$ ions, respectively $(\mathrm{LOD}=3.3 \times$ standard deviation of blank/slope $(n=3))$. Additionally, the accuracy and precision of the as-synthesized GSH CD-hydrogel film for $\mathrm{Pb}^{2+}, \mathrm{Fe}^{3+}$, and $\mathrm{Mn}^{2+}$ ions were mentioned in Supporting Information of Table S1. These results indicate that GSH CD-agarose hydrogel film acts as a promising solid probe for visual detection of $\mathrm{Pb}^{2+}, \mathrm{Fe}^{3+}$, and $\mathrm{Mn}^{2+}$ ions

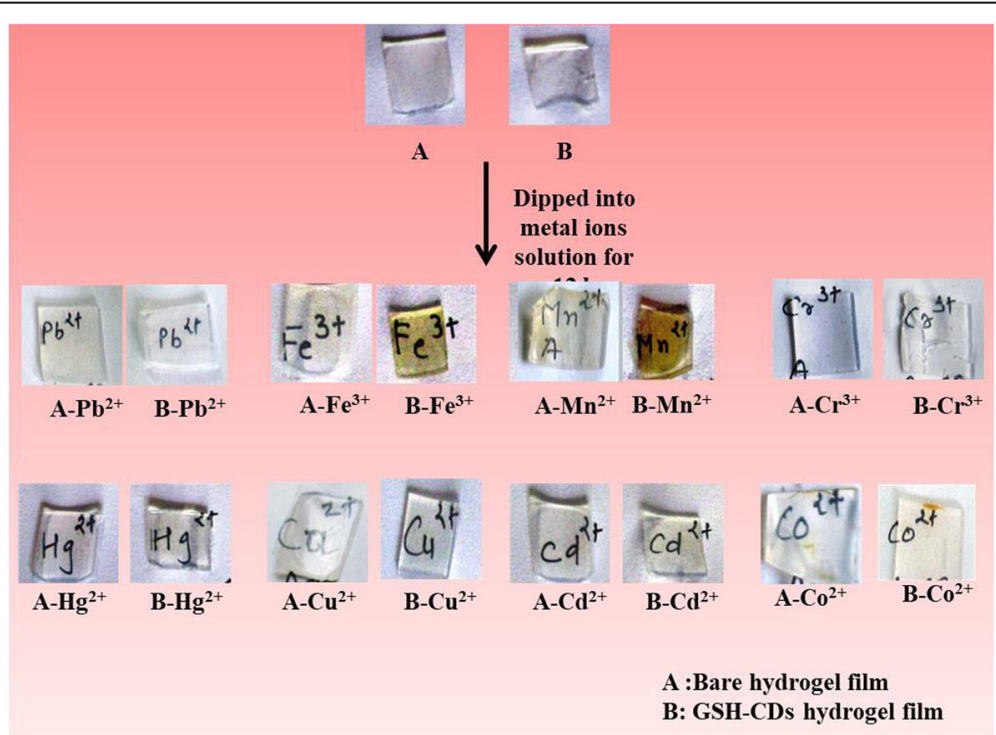

Fig. 4 Photographic images of bare agarose hydrogel and GSH CD-agarose hydrogel film for visual detection of metal ions $\left(\mathrm{Pb}^{2+}, \mathrm{Fe}^{3+}, \mathrm{Mn}^{2+}\right.$, $\mathrm{Cr}^{3+}, \mathrm{Hg}^{2+}, \mathrm{Cu}^{2+}, \mathrm{Cd}^{2+}$, and $\mathrm{Co}^{2+}$ ions, $\left.1.0 \mathrm{mM}\right)$ 


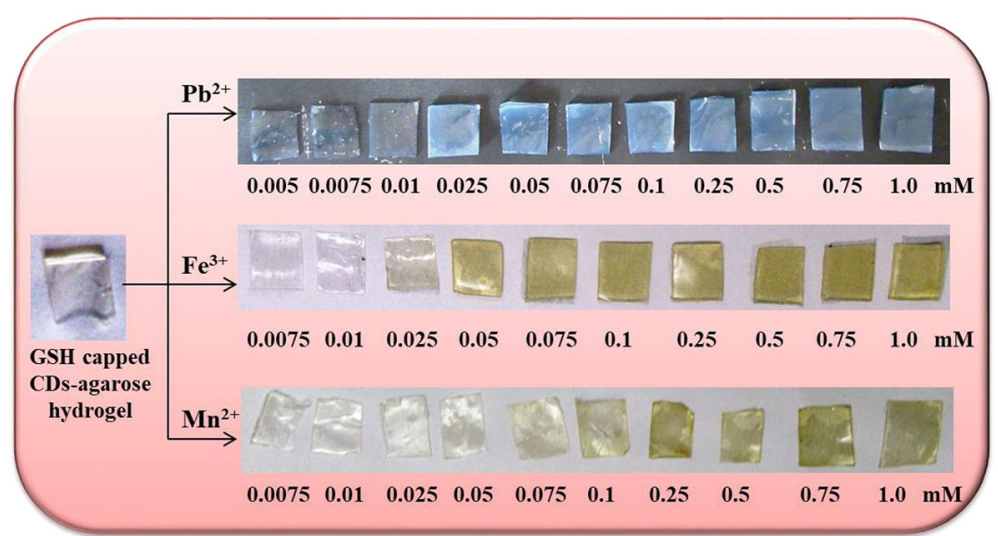

Fig. 5 Photographic images of GSH CD-agarose hydrogel films treated with different concentrations of $\mathrm{Pb}^{2+}(0.005-1.0 \mathrm{mM}), \mathrm{Fe}^{3+}(0.0075-1.0$ $\mathrm{mM})$, and $\mathrm{Mn}^{2+}(0.0075-1.0 \mathrm{mM})$
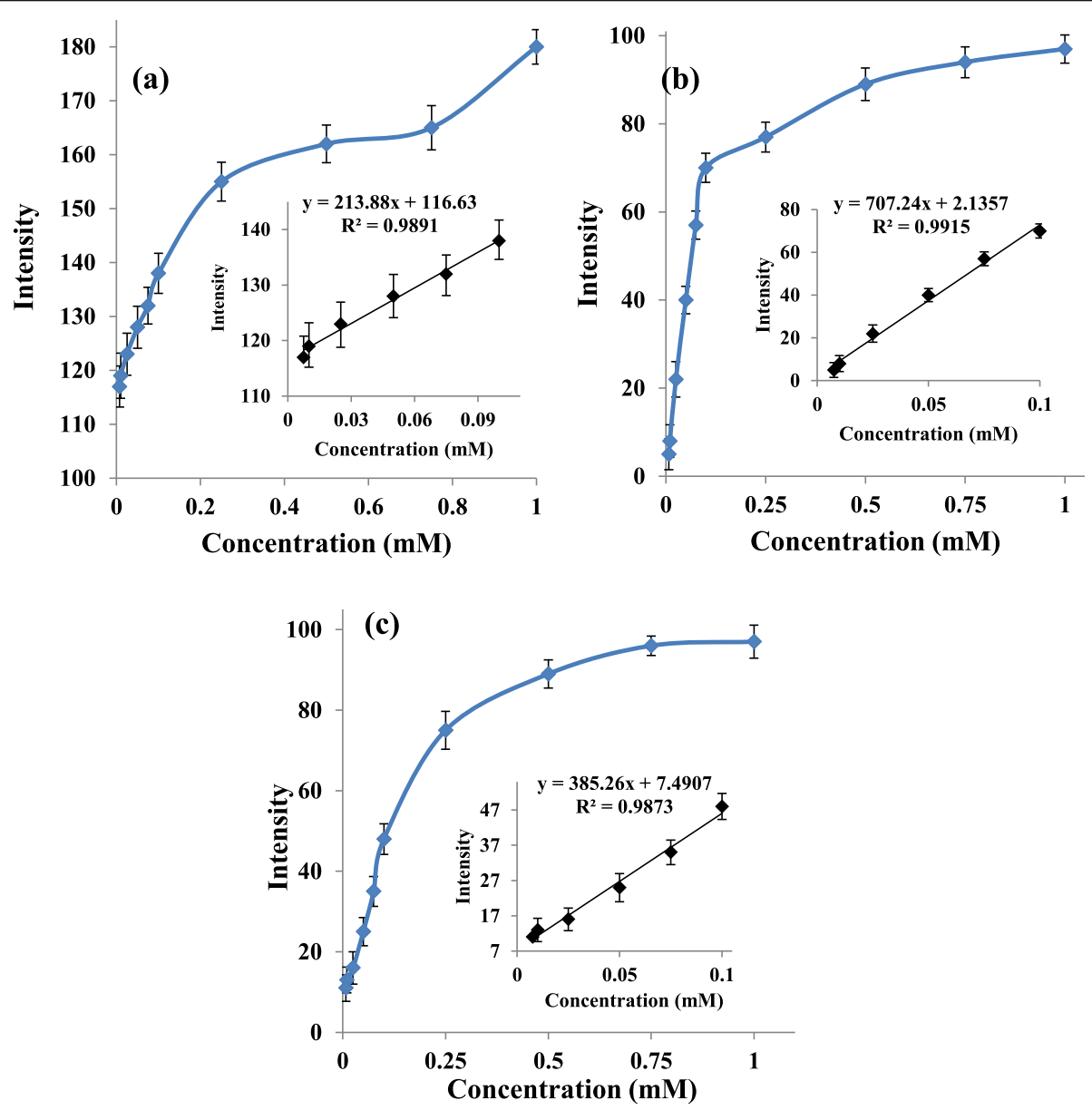

Fig. 6 Calibration graph plotted between the color intensities of hydrogel films and different concentrations of a $\mathrm{Pb}^{2+}$ ion in the range of $0.005-$ $0.075 \mathrm{mM}, \mathbf{b} \mathrm{Fe}^{3+}$ ion in the range of $0.0075-0.1 \mathrm{mM}$, and $\mathbf{c ~} \mathrm{Mn}^{2+}$ ion in the range of $0.0075-0.1 \mathrm{mM}$ 
without the aid of sophisticated instruments, which avoids tedious sample preparations. As shown in Table 1, GSH CD-agarose hydrogel film as a probe was compared with gold $\mathrm{Au}$ ) interdigitated electrodes, $\mathrm{Au}$ nanoparticles (Au NPs), AT-cut Au-coated quartz crystal, graphene quantum dots (GQDs) and Au NPs, L-tyrosine silver NPs (Ag NPs), and poly-L- $\alpha$-glutamic acid (PGA) for $\mathrm{Pb}^{2+}$ ion (Cui et al. 2016; Teh et al. 2014; Niu et al. 2018; Annadhasan et al. 2014; $\mathrm{Hu}$ and Elioff 2018). For $\mathrm{Fe}^{3+}$ ion, various fluorometric methods were based on GQDs, sulphur-doped carbon dots (C-dots) and carbon quantum dots (CQDs), cranberry CDs, citric acid and $\left(\mathrm{NH}_{4}\right)_{2} \mathrm{HPO}_{4} \mathrm{CDs}$, and alginic acid (AA) and ethane diamine (EDA) CDs (Zhang et al. 2019; Xu et al. 2015; Wu et al. 2018; Zulfajri et al. 2019; Chandra et al. 2016; Liu et al. 2015). Various colorimetric methods based on 4-mercaptobenzoic acid (4-MBA) and melamine (MA)modified Ag NPs, L-tyrosine Ag NPs and $\beta$-cyclodextrin Ag NPs, $\mathrm{NH}_{2}$-MIL-125(Ti)/carbon paste electrode (CPE) photoirradiation cathodic stripping voltammetry (CSV) method, and carboxymethyl cellulose (CMC)/Tb(III) nanocomposite fluorometric method were compared with GSH CD-agarose hydrogel film for $\mathrm{Mn}^{2+}$ ion
(Annadhasan et al. 2014; Xu et al. 2014; Ye et al. 2018; $\mathrm{Hu}$ et al. 2014). Furthermore, GSH CD-hydrogel film as a detection probe was used for standard samples of 1 $\mathrm{mM}$ of $\mathrm{Pb}^{2+}, \mathrm{Fe}^{3+}$, and $\mathrm{Mn}^{2+}$ and treated the same as described for the prepared solutions $\left(\mathrm{Pb}^{2+}, \mathrm{Fe}^{3+}\right.$, and $\mathrm{Mn}^{2+}$, $1 \mathrm{mM}$ ), and as shown in Supporting Information of Table S2, the obtained data of standard samples were well matched with the prepared metal ion solutions.

\section{Conclusions}

In conclusion, a simple synthetic protocol was established for the fabrication of GSH CD-agarose hydrogel film for the visual detection of three metal ions $\left(\mathrm{Pb}^{2+}\right.$, $\mathrm{Fe}^{3+}$, and $\mathrm{Mn}^{2+}$ ) without the aid of any analytical instrument. The GSH-capped CDs were successfully incorporated into the agarose hydrogel system and characterized by various spectroscopic techniques. These three metal ions effectively induced color changes $\mathrm{Pb}^{2+}$ ion $\rightarrow$ white, $\mathrm{Fe}^{3+}$ ion $\rightarrow$ brown, and $\mathrm{Mn}^{2+}$ ion $\rightarrow$ dark brown color) of GSH CD-agarose hydrogel film, which can easily be observed with the naked eye. This color intensities of hydrogel film exhibited good linearities in the range of $0.005-0.075 \mathrm{mM}$ for $\mathrm{Pb}^{2+}$ ion and of $0.0075-0.1 \mathrm{mM}$ for

Table 1 Evaluation for the detection of $\mathrm{Pb}^{2+}, \mathrm{Fe}^{3+}$, and $\mathrm{Mn}^{2+}$ ion using GSH CD-agarose hydrogel film with various other established methods

\begin{tabular}{|c|c|c|c|c|}
\hline Method & Probe & Linear range $(\mu \mathrm{M})$ & $\mathrm{LOD}(\mu \mathrm{M})$ & References \\
\hline \multicolumn{5}{|l|}{$\overline{\mathrm{Pb}^{2+}}$} \\
\hline Electrochemical & Au interdigitated electrodes & $0.01-0.1$ & 0.00661 & Cui et al. 2016 \\
\hline $\begin{array}{l}\text { Quartz crystal microbalance } \\
\text { with dissipation monitoring }\end{array}$ & $\begin{array}{l}\text { Au NP; AT-cut Au-coated } \\
\text { quartz crystal }\end{array}$ & $0.046-3$ & 0.014 & Teh et al. 2014 \\
\hline Fluorescence & GQDs and Au NPs & $0.05-4$ & 0.0167 & Niu et al. 2018 \\
\hline Colorimetric & L-tyrosine Ag NPs & $0.016-0.1$ & 0.016 & Annadhasan et al. 2014 \\
\hline Fluorescence & PGA & $66-261$ & 0.098 & Hu and Elioff 2018 \\
\hline Colorimetric- hydrogel film & GSH CD-agarose hydrogel film & $5.0-75$ & 1.3 & Present method \\
\hline \multicolumn{5}{|l|}{$\mathrm{Fe}^{3+}$} \\
\hline Fluorescence & GQDs & $3.5-670$ & 1.6 & Zhang et al. 2019 \\
\hline Fluorescence & S-doped C-dots & $1.0-500$ & 0.1 & Xu et al. 2015 \\
\hline Fluorescence & S-doped CQDs & $100-1000$ & 0.177 & Wu et al. 2018 \\
\hline Fluorescence & Cranberry bean-derived CDs & $30-600$ & 9.55 & Zulfajri et al. 2019 \\
\hline Fluorescence & Citric acid and $\left(\mathrm{NH}_{4}\right)_{2} \mathrm{HPO}_{4} \mathrm{CDs}$ & $20-200$ & 20 & Chandra et al. 2016 \\
\hline Fluorescence & $\mathrm{AA}$ and $\mathrm{EDA} C D \mathrm{~s}$ & $0-50$ & 10.98 & Liu et al. 2015 \\
\hline Colorimetric hydrogel film & GSH CD-agarose hydrogel film & $7.5-100$ & 2.5 & Present method \\
\hline \multicolumn{5}{|l|}{$\mathrm{Mn}^{2+}$} \\
\hline Colorimetric & 4-MBA and MA-modified Ag NPs & $0.5-10$ & 0.05 & Zhou et al. 2012 \\
\hline Colorimetric & L-tyrosine Ag NPs & $0.016-0.5$ & 0.016 & Annadhasan et al. 2014 \\
\hline Photoirradiation CSV & $\mathrm{NH}_{2}-\mathrm{MIL}-125(\mathrm{Ti}) / \mathrm{CPE}$ & $0.01-10$ & 0.004 & Xu et al. 2014 \\
\hline Fluorescence & $\mathrm{CMC} / \mathrm{Tb}$ (III) nanocomposite & $0.1-100$ & 0.046 & Ye et al. 2018 \\
\hline Colorimetric & $\beta$-Cyclodextrin Ag NPs & $1.0-1000$ & 0.5 & Hu et al. 2014 \\
\hline Colorimetric hydrogel film & GSH CD-agarose hydrogel film & $7.5-100$ & 2.1 & Present method \\
\hline
\end{tabular}


$\mathrm{Fe}^{3+}$ and $\mathrm{Mn}^{2+}$ ions with a correlation coefficient of 0.9891, 0.9915, and 0.9873 for $\mathrm{Pb}^{2+}, \mathrm{Fe}^{3+}$, and $\mathrm{Mn}^{2+}$ ions, respectively, with increasing concentrations of the three metal ions. The detection limits were 1.3, 2.5, and $2.1 \mu \mathrm{M}$ for $\mathrm{Pb}^{2+}, \mathrm{Fe}^{3+}$, and $\mathrm{Mn}^{2+}$ ion, respectively. The fabricated GSH CD-agarose hydrogel film acts as a promising solid probe for the visual detection of the three metal ions, which can be used as a portable on-site solid probe for the detection of the three metal ions in environmental samples without any complicated sample preparations.

\section{Supplementary information}

Supplementary information accompanies this paper at https://doi.org/10. 1186/s40543-020-00208-8.

Additional file 1: Supporting Information of Glutathione capped Syzygium cumini Carbon Dots Amalgamated Agarose Hydrogel Film for Naked-eye Detection of Heavy Metal Ions

\section{Abbreviations}

CDs: Carbon dots; DLS: Dynamic light scattering; FT-IR: Fourier transform infrared; GSH: Glutathione; HR-TEM: High-resolution transmission electron microscopy; $\mathrm{NaOH}$ : Sodium hydroxide; UV: Ultraviolet

\section{Authors' contributions}

JRB carried out this work at the Applied Chemistry Department, S. V. National Institute of Technology, Surat, 395007, India. T-JP discussed the analytical characteristics of the prepared hydrogels. SKK supervised the entire work and edited the manuscript. All authors read and approved the final manuscript.

\section{Funding}

This work was financially supported by the Department of Science and Technology, Government of India (EMR/2016/002621/PC), and the Director, SVNIT, Surat, Gujarat, India.

\section{Availability of data and materials}

All the experiments were carried out at the Applied Chemistry Department, SVNIT, Surat, India. Analytical data (UV-visible, FT-IR, DLS, and fluorescence) were measured, which are available at the Applied Chemistry Department, SVNIT, Surat. All the data are available from the corresponding author (Dr. Suresh Kumar Kailasa) of this manuscript. HR-TEM images were measured at the Central Salt and Marine Chemicals Research Institute, Bhavnagar, Gujarat. Research data have been provided in the manuscript and supporting information files.

\section{Competing interests}

The authors declare that they have no competing interests.

\section{Author details \\ ${ }^{1}$ Department of Applied Chemistry, S. V. National Institute of Technology, Surat 395007, India. ${ }^{2}$ Department of Chemistry, Institute of Interdisciplinary Convergence Research, Research Institute of Halal Industrialization Technology, Chung-Ang University, 84 Heukseok-ro, Dongjak-gu, Seoul 06974, Republic of Korea.}

Received: 17 October 2019 Accepted: 14 February 2020 Published online: 24 April 2020

\section{References}

Afkhami A, Felehgari FS, Madrakian T, Ghaedi H, Rezaiwala M. Fabrication and application of a new modified electrochemical sensor using nano-silica and a newly synthesized Schiff base for simultaneous determination of $\mathrm{Cd}^{2+}$, $\mathrm{Cu}^{2+}$ and $\mathrm{Hg}^{2+}$ ions in water and some foodstuff samples. Anal Chim Acta. 2013;771:21-30
Annadhasan M, Muthukumarasamyvel T, Sankar Babu VR, Rajendiran N. Green synthesized silver and gold nanoparticles for colorimetric detection of $\mathrm{Hg}^{2+}$, $\mathrm{Pb}^{2+}$, and $\mathrm{Mn}^{2+}$ in aqueous medium. ACS Sustain Chem Eng. 2014;2:887-96.

Array G, Merkoci A. Nanomaterials application in electrochemical detection of heavy metals. Electrochim Acta. 2012;84:49-61.

Bernalte E, Marín Sánchez C, Pinilla GE. Determination of mercury in ambient water samples by anodic stripping voltammetry on screen-printed gold electrodes. Anal Chim Acta. 2011;689:60-4.

Bhamore JR, Jha S, Singhal RK, Kailasa SK. Synthesis of water dispersible fluorescent carbon nanocrystals from Syzygium cumini fruits for the detection of $\mathrm{Fe}^{3+}$ ion in water and biological samples and imaging of Fusarium avenaceum cells. J Fluoresc. 2016;27:125-34.

Callender E. Heavy metals in the environment - historical trends. Treatise Geochem. 2003;9:67-105.

Chandra S, Laha D, Pramanik A, Chowdhuri AR, Karmakar P, Sahu SK. Synthesis of highly fluorescent nitrogen and phosphorus doped carbon dots for the detection of $\mathrm{Fe}^{3+}$ ions in cancer cells. Luminescence. 2016;31:81-7.

Cui H, Xiong X, Gao B, Chen Z, Luo Y, He F, Deng S, Chen L. A novel impedimetric biosensor for detection of lead (II) with low-cost interdigitated electrodes made on PCB. Electroanal. 2016;28:2000-6.

Cui L, Wu J, Ju H. Electrochemical sensing of heavy metal ions with inorganic, organic and bio-materials. Biosens Bioelectron. 2015;63:276-86.

Directive, 2013/35/EU of the European Parliament and of the Council, 2013.

Gogoi N, Barooah M, Majumdar G, Chowdhury D. Carbon dots rooted agarose hydrogel hybrid platform for optical detection and separation of heavy metal ions. ACS Appl Mater Interfaces. 2015;7:3058-67.

Gong T, Liu J, Liu X, Liu J, Xiang J, Wu Y. A sensitive and selective sensing platform based on CdTe QDs in the presence of L-cysteine for detection of silver, mercury and copper ions in water and various drinks. Food Chem. 2016:213:306-12.

Gu B, Ye M, Nie L, Fang Y, Wang Z, Zhang X, Zhang H, Zhou Y, Zhang Q. Organic-dye-modified upconversion nanoparticle as a multichannel probe to detect $\mathrm{Cu}^{2+}$ in living cells. ACS Appl Mater Interfaces. 2018;10:1028-32.

Gu B, Zhang Q. Recent advances on functionalized upconversion nanoparticles for detection of small molecules and ions in biosystems. Adv Sci. 2018;5: 1700609-24.

Gu B, Zhou Y, Zhang X, Liu X, Zhang Y, Marks R, Zhang H, Liu X, Zhang Q. Thiazole derivative-modified upconversion nanoparticles for $\mathrm{Hg}^{2+}$ detection in living cells. Nanoscale. 2016a;8:276-82.

Gu P-Y, Wang Z, Zhang Q. Azaacenes as active elements for sensing and bio applications. J Mater Chem B. 2016b;4:7060-74.

Gumpu MB, Sethuraman S, Krishnan UM, Rayappan JBB. A review on detection of heavy metal ions in water - an electrochemical approach. Sensors Actuators B Chem. 2015;213:515-33.

Hong W, Li W, Hu X, Zhao B, Zhang F, Zhang D. Highly sensitive colorimetric sensing for heavy metal ions by strong polyelectrolyte responsive photonic crystals. J Mater Chem. 2011;21:17193-201.

$\mathrm{Hu}$ J, Elioff MS. Detection of $\mathrm{Zn}^{2+}, \mathrm{Cd}^{2+}, \mathrm{Hg}^{2+}$, and $\mathrm{Pb}^{2+}$ ions through label-free poly-L-glutamic acid. Talanta. 2018;188:552-61.

Hu R, Zhang L, Li H. A highly sensitive and selective colorimetric sensor for the detection of $\mathrm{Mn}^{2+}$ based on supramolecular silver nanoparticle clusters. New J Chem. 2014;38:2237-40

Kenawy IMM, Hafez MAH, AkI MA, Lashein RR. Determination by AAS of some trace heavy metal ions in some natural and biological samples after their preconcentration using newly chemically modified chloromethylated polystyrene-PAN ion-exchanger. Anal Sci. 2000;16:493-500.

Kim HN, Ren WX, Kim JS, Yoon J. Fluorescent and colorimetric sensors for detection of lead, cadmium, and mercury ions. Chem Soc Rev. 2012;41:3210-44.

Lin H, Zou Y, Huang Y, Chen J, Zhang WY, Zhuang Z, Jenkins G, Yang CJ. DNAzyme crosslinked hydrogel: a new platform for visual detection of metal ions. Chem Commun. 2011:47:9312-4.

Liu Y, Liu Y, Park S-J, Zhang Y, Kim T, Chae S, Park M, Kim H-Y. One-step synthesis of robust nitrogen-doped carbon dots: acid-evoked fluorescence enhancement and their application in $\mathrm{Fe}^{3+}$ detection. J Mater Chem A. 2015; 3:17747-54.

Losev VN, Buyko OV, Trofimchuk AK, Zuy ON. Silica sequentially modified with polyhexamethylene guanidine and Arsenazo I for preconcentration and ICPOES determination of metals in natural waters. Micro Chem J. 2015;123:84-9.

Nam J, Jung I-B, Kim B, Lee S-M, Kim S-E, Lee K-N, Shin D-S. A colorimetric hydrogel biosensor for rapid detection of nitrite ions. Sensors Actuators $B$ Chem. 2018;270:112-8. 
Niu X, Zhong Y, Chen R, Wang F, Liu Y, Luo D. A "turn-on" fluorescence sensor for $\mathrm{Pb}^{2+}$ detection based on graphene quantum dots and gold nanoparticles. Sensors Actuators B Chem. 2018;255:1577-81.

Pohl P. Determination of metal content in honey by atomic absorption and emission spectrometries. Trends Anal Chem. 2009;28:117-28.

Prabhakar S, Singh AK, Pooni DS. Effect of environmental pollution on animal and human health: a review. Ind J Anim Sci. 2012;82:244-55.

Pujol L, Evrard D, Serrano KG, Freyssinier M, Cizsak AR, Gros P. Electrochemical sensors and devices for heavy metals assay in water: the French groups' contribution. Front. Chem., Anal. Chem. 2014;19:1-24.

Roy SP. Overview of heavy metals and aquatic environment with notes on their recovery. Ecoscan. 2010;4:235-40.

Sitko R, Janik P, Zawisza B, Talik E, Margui E, Queralt I. Green approach for ultratrace determination of divalent metal ions and arsenic species using total-reflection $X$-ray fluorescence spectrometry and mercapto-modified graphene oxide nanosheets as a novel adsorbent. Anal Chem. 2015;87:3535-42.

Standard methods for the examination of water \& wastewater, 2012. American Public Health Association (APHA), American Water Works Association (AWWA) \& Water Environment Federation 22 (WEF).

Teh HB, Li H, Li SFY. Highly sensitive and selective detection of $\mathrm{Pb}^{2+}$ ions using a novel and simple DNAzyme-based quartz crystal microbalance with dissipation biosensor. Analyst. 2014;139:5170-5.

Trindade AS, Dantas AF, Lima DC, Ferreira SLC, Teixeira LS. Multivariate optimization of ultrasound-assisted extraction for determination of $\mathrm{Cu}, \mathrm{Fe}, \mathrm{Ni}$ and $\mathrm{Zn}$ in vegetable oils by high-resolution continuum source atomic absorption spectrometry. Food Chem. 2015:185:145-50.

Ullah F, Othman MBH, Javed F, Ahmad Z, Md AH. Classification, processing and application of hydrogels: a review. Mater Sci Eng C. 2015;57:414-33.

Wang H, Wu ZK, Chen BB, He M, Hu B. Chip-based array magnetic solid phase microextraction on-line coupled with inductively coupled plasma mass spectrometry for the determination of trace heavy metals in cells. Analyst. 2015;140:5619-26.

WHO, Guidelines for Drinking-water Quality, 4th edition, 2011.

Wu F, Yang M, Zhang H, Zhu S, Zhu X, Wang K. Facile synthesis of sulfur-doped carbon quantum dots from vitamin $\mathrm{B} 1$ for highly selective detection of $\mathrm{Fe}^{3-}$ ion. Opt Mater. 2018;77:258-63.

Xu Q, Pu P, Zhao J, Dong C, Gao C, Chen Y, Chen J, Liua Y, Zhou H. Preparation of highly photoluminescent sulfur doped carbon dots for Fe(III) detection. J Mater Chem A. 2015;3:542-6.

Xu Q, Wang Y, Jin G, Jin D, Li K, Mao A, Hu X. Photooxidation assisted sensitive detection of trace $\mathrm{Mn}^{2+}$ in tea by $\mathrm{NH}_{2}-\mathrm{MIL}-125$ (Ti) modified carbon paste electrode. Sensors Actuators B Chem. 2014;201:274-80.

Yan Z, Tian C, Qu X, Shen W, Ye B. DNA-functionalized photonic crystal microspheres for multiplex detection of toxic metal ions. Colloids Surf B. 2017;154:142-9.

Ye B-F, Zhao Y-J, Cheng Y, Li T-T, Xie Z-Y, Zhao X-W, Gu Z-Z. Colorimetric photonic hydrogel aptasensor for the screening of heavy metal ions. Nanoscale. 2012:4:5998-6003.

Ye J, Zhang M, Xiong J. Fluorescence probe based carboxymethyl cellulose/Tb(III) nanocomposites for detection of $\mathrm{Mn}^{2+}$ with simpleness, rapidness and high sensitivity. Carbohydr. 2018;190:156-61.

Zhang Y, Yang X, Pu Y, Cheng W, Lin S, Shao Z, Liao X. Selective, sensitive and label-free detection of $\mathrm{Fe}^{3+}$ ion in tap water using highly fluorescent graphene quantum dots. J Fluoresc. 2019;29:541-8.

Zhou Y, Zhao H, Li C, He P, Peng W, Yuan L, Zeng L, He Y. Colorimetric detection of $\mathrm{Mn}^{2+}$ using silver nanoparticles cofunctionalized with 4-mercaptobenzoic acid and melamine as a probe. Talanta. 2012;97:331-5.

Zhu Z, Wu C, Liu H, Zou Y, Zhang X, Kang H, Yang CJ, Tan W. An aptamer crosslinked hydrogel as a colorimetric platform for visual detection. Angew Chem Int Ed. 2010;49:1052-6.

Zulfajir M, Gedda G, Chang C-J, Chang Y-P. Huang GG. Cranberry beans derived carbon dots as a potential fluorescence sensor for selective detection of $\mathrm{Fe}^{3+}$ ions in aqueous solution. ACS Omega. 2019;4:13,15382-92.

\section{Publisher's Note}

Springer Nature remains neutral with regard to jurisdictional claims in published maps and institutional affiliations.

\section{Submit your manuscript to a SpringerOpen ${ }^{\circ}$ journal and benefit from:}

- Convenient online submission

Rigorous peer review

- Open access: articles freely available online

- High visibility within the field

- Retaining the copyright to your article

Submit your next manuscript at $\boldsymbol{\nabla}$ springeropen.com 